\title{
Whole-body diffusion-weighted MRI for staging of women with cancer during pregnancy: a pilot study
}

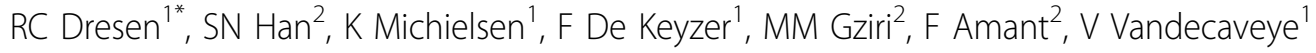 \\ From International Cancer Imaging Society Meeting and 15th Annual Teaching Course (ICIS 2015) \\ London, UK. 5-7 October 2015
}

\begin{abstract}
Aim
To evaluate whole-body diffusion weighted magnetic resonance imaging (WB-DWI) for staging of women with cancer during pregnancy.

\section{Methods}

Twenty patients diagnosed with cancer during pregnancy underwent WB-DWI additional to conventional imaging in this prospective single centre study. Reproducibility of WB-DWI between 2 readers was evaluated using Cohen's $\kappa$ statistics and accuracy was compared to conventional imaging for assessing primary tumour site, nodal metastases and visceral metastases. Histopathology after surgery or biopsy was the primary reference standard.
\end{abstract}

\section{Results}

Ten patients had breast cancer, 3 lymphoma, 2 cervical uterine cancer, 1 ovarian borderline tumour, 2 colon cancer, 1 lung cancer and 1 a conjunctival tumour. The WB-DWI readers showed very good agreement for lesion detection, $\kappa=0.94$. With WB-DWI, reader 1 detected 38 of 41 malignant lesions, reader 2 thirty-nine lesions and conventional imaging 27. WB-DWI showed sensitivity of $95 \%$ (95\% CI: 74-99) for both readers and specificity up to $99 \%$ (95\% CI: 76-99) compared to $50 \%$ sensitivity (95\% CI: 28-72) with 100\% (95\% CI: 97-100) specificity for conventional imaging. For staging distant metastases, WB-DWI sensitivities were 66.7\% (95\% CI: 13-98) and 100\% (95\% CI: 40-100) respectively for reader 1 and 2 with specificities of $94.1 \%$ (95\% CI: 69 -

\footnotetext{
* Correspondence: elleke.dresen@uzleuven.be

'Department of Radiology, Leuven Cancer Institute, University Hospitals Leuven, KU Leuven, Leuven, Belgium

Full list of author information is available at the end of the article
}

99) and 100\% (95\% CI: 40-100) compared to sensitivity of $33.3 \%$ (95\% CI: $1.7-87)$ and specificity of $100 \%$ (95\% CI: 77-100) for conventional imaging.

\section{Conclusion}

WB-DWI is feasible for single-step non-invasive imaging based cancer staging during pregnancy showing additional value to conventional imaging procedures for detecting distant and nodal metastases.

\section{Authors' details}

'Department of Radiology, Leuven Cancer Institute, University Hospitals Leuven, KU Leuven, Leuven, Belgium. ²Department of Obstetrics and Gynaecology, Division of Gynaecologic Oncology, Leuven Cancer Institute, University Hospitals Leuven, KU Leuven, Leuven, Belgium.

Published: 2 October 2015

doi:10.1186/1470-7330-15-S1-P50

Cite this article as: Dresen et al:: Whole-body diffusion-weighted MRI for staging of women with cancer during pregnancy: a pilot study. Cancer Imaging 2015 15(Suppl 1):P50.

Submit your next manuscript to BioMed Central and take full advantage of:

- Convenient online submission

- Thorough peer review

- No space constraints or color figure charges

- Immediate publication on acceptance

- Inclusion in PubMed, CAS, Scopus and Google Scholar

- Research which is freely available for redistribution

Submit your manuscript at www.biomedcentral.com/submit 